\title{
Polymorphism rs368234815 of interferon lambda 4 gene and spontaneous clearance of hepatitis $C$ virus in haemodialysis patients: a case-control study
}

Alicja E. Grzegorzewska ${ }^{1 *}$ D, Adrianna Mostowska², Monika K. Świderska', Wojciech Marcinkowski ${ }^{3}$, Ireneusz Stolarek ${ }^{4}$, Marek Figlerowicz ${ }^{4}$ and Paweł P. Jagodziński ${ }^{2}$

\begin{abstract}
Background: In non-uremic subjects, IFNL4 rs368234815 predicts HCV clearance. We investigated whether rs368234815 is associated with spontaneous HCV clearance in haemodialysis patients and whether it is a stronger predictor of HCV resolution than the IFNL polymorphisms already associated with HCV clearance in dialysis subjects. We also evaluated an association of rs368234815 with patients' survival and alterations in transcription factor binding sites (TFBS) caused by IFNL polymorphisms.
\end{abstract}

Methods: Among 161 haemodialysis patients with positive anti-HCV antibodies, 68 (42.2\%) spontaneously resolved HCV infection, whereas 93 remained HCV RNA positive. Patients were tested for near IFNL3 rs12980275, IFNL3 rs4803217, IFNL4 rs12979860, IFNL4 rs368234815, and near IFNL4 rs8099917. IFNL4 rs368234815 polymorphism (TT/TT, $\Delta \mathrm{G} / T, \Delta \mathrm{G} / \Delta \mathrm{G}$ ) was genotyped by restriction fragment length polymorphism analysis; other IFNL polymorphisms by high resolution melting curve analysis. We used the Kaplan-Meier method with the log-rank test for survival analysis. In silico analysis included the use of ENCODE TFBS ChIP-seq data, HOCOMOCO, JASPAR CORE, and CIS-BP databases, and FIMO software.

Results: The probability $(\mathrm{OR}, 95 \% \mathrm{Cl}, \mathrm{P})$ of spontaneous HCV clearance for $\mathrm{rs} 368234815 \mathrm{~T} / \mathrm{TT}$ patients was higher than for the $\Delta \mathrm{G}$ allele carriers $(2.63,1.38-5.04,0.003)$. This probability for other major homozygotes varied between 2.80, 1.45-5.43, 0.002 for rs 12980275 and 2.44, 1.27-4.69, 0.007 for rs 12979860. In the additive model, rs 368234815 $\Pi \pi / T$ was the strongest predictor of HCV clearance $(6.38,1.69-24.2,0.003)$. Survival analysis suggested an association of the $\Delta \mathrm{G}$ allele with mortality due to neoplasms (log-rank $P=0.005$ ). The rs368234815 $\Delta \mathrm{G}$ allele caused TFBS removal for PLAGL1.

(Continued on next page)

\footnotetext{
*Correspondence: alicja_grzegorzewska@yahoo.com

${ }^{1}$ Department of Nephrology, Transplantology and Internal Diseases, Poznan University of Medical Sciences, Przybyszewskiego 49, 60-355 Poznań, Poland Full list of author information is available at the end of the article
} 


\begin{abstract}
(Continued from previous page)
Conclusions: In haemodialysis patients, the association of rs368234815 with the spontaneous HCV clearance is better than that documented for other IFNL3/IFNL4 polymorphisms only in the additive mode of inheritance. However, identifying the homozygosity in the variant $\Delta G$ allele of rs 368234815 means a more potent prediction of persistent HCV infection in haemodialysis subjects that we observe in the case of the variant homozygosity of other tested IFNL3/IFNL4 polymorphisms. Removal of PLAGL1 TFBS in subjects harbouring the rs368234815 $\triangle$ G allele may contribute to cancer susceptibility. The association of rs368234815 with cancer-related mortality needs further studies in HCV-exposed subjects.
\end{abstract}

Keywords: Haemodialysis, Hepatitis C virus, Interferon- $\lambda 4$ gene, Spontaneous viral clearance, Transcription factors

\section{Background}

Since 2002, single nucleotide polymorphisms (SNPs) located in the interferon- $\lambda$ genetic region (IFNL) on chromosome $19 \mathrm{q} 13$ are associated with antiviral protection $[1,2]$. In humans, polymorphisms of the interferon$\lambda 3$ gene (IFNL3) or located near IFNL3 (mainly rs12979860, rs4803217, rs8099917, rs12980275) became established genetic markers of spontaneous and PEGylated interferon-based antiviral drug-induced hepatitis $\mathrm{C}$ virus $(\mathrm{HCV})$ clearance [3-8].

In 2013, Prokunina-Olsson et al. [9] discovered the interferon- $\lambda 4$ gene (IFNL4) located on chromosome $19 \mathrm{q} 13.2$ upstream of IFNL3 that harbours the dinucleotide frame-shift variant rs368234815 (TT/ $\Delta \mathrm{G})$, named initially ss469415590. The polymorphism rs368234815, located within the first IFNL4 exon, is classified as a deletion/insertion genetic variation $(\mathrm{TT} / \Delta \mathrm{G})$. The IFNL4 rs368234815 polymorphism controls a generation of the functional protein - interferon- $\lambda 4$ (IFN- $\lambda 4$ ) [9]. The ancestral IFNL4 $\triangle \mathrm{G}$ allele creates an open reading frame for IFN- $\lambda 4$, whereas the alternative IFNL4 TT variant eliminates IFN- $\lambda 4$ [9]. IFNL4 rs368234815 influences the signalling pathway between interferon- $\lambda 3$ receptor 1 (IFN- $\lambda$ R1) and interferon-stimulated response element (ISRE). Overexpression of IFNL4 suppresses IFNL3 induction and promoter activation [10]. Transient IFNL4 overexpression in a hepatoma cell line induced signal transducer and activator of transcription (STAT) $1 /$ STAT2 phosphorylation and expression of interferonstimulated genes (ISG) [9]. Low intracellular expression of IFN- $\lambda 4$ induces IFN- $\lambda$ expression, leading to the Janus activated kinase (JAK)-STAT signalling and expression of ISG [11]. The favourable outcome of HCV infection correlates with the inability to encode IFN- $\lambda 4[9,10]$.

There is a high linkage disequilibrium (LD) between rs368234815 and rs12979860, previously designated IFNL3 rs12979860 [12]. At present, we know that rs12979860 lies in the intron 1 of IFNL4 and has to be related to IFNL4. Since 2013, we know that rs12979860 is associated with HCV spontaneous or therapeutic eradication due to its high LD with IFNL4 rs368234815 (TT/ $\Delta G)$ [9]. In Ferraris et al. [11], IFNL4 $\Delta G$ showed a
$100 \%$ correlation with the TT genotype of rs12979860. Compared to rs12979860, rs368234815 appeared similarly $[9,13]$ or more strongly [14-16] associated with HCV clearance. Unfavourable (variant) alleles of both rs12979860 and rs368234815 were also associated with reduced clearance of RNA viruses from the respiratory tract [17]. IFNL3 rs4803217, altering IFNL3 mRNA stability [3], is also in a substantial LD with IFNL4 rs368234815. However, rs4803217 seems to be less strongly associated with $\mathrm{HCV}$ clearance than IFNL4 rs368234815 [18].

An association between IFNL polymorphisms and $\mathrm{HCV}$ clearance was studied mainly in non-uremic subjects $[4-10,15,16,18,19]$. The meta-analysis by Xie et al. [20] revealed that the rs368234815 TT/TT genotype correlated with the sustained virologic response (SVR) to treatment with PEGylated interferon plus ribavirin in $\mathrm{HCV}-1 / 4$-infected Caucasian patients but not in HCV-2/3-infected Caucasian patients. Conversely, the rs368234815 $\Delta \mathrm{G} / \Delta \mathrm{G}$ genotype was linked to treatment failure in Caucasian patients, regardless of the $\mathrm{HCV}$ genotype. The rs368234815 $\Delta \mathrm{G}$ allele was also a negative predictor of efficacy of direct-acting antivirals applied in HCV patients [21-23].

Reports concerning mentioned above associations in patients suffering from haemodialysis (HD)-dependent end-stage renal disease (ESRD) are scarce [24-27], and, to our knowledge, were not conducted for IFNL4 rs368234815, currently designated as the most promising predictor of $\mathrm{HCV}$ resolution [18]. Uremic milieu changes the expression of genes [28]. Therefore, it is worthy of investigating whether the impact of IFNL polymorphic variants on $\mathrm{HCV}$ clearance is comparable in HD patients to that observed in non-uremic populations.

Our study's primary purpose was to recognize the IFNL3/IFNL4 impact on spontaneous $\mathrm{HCV}$ elimination in HD patients with particular attention paid to IFNL4 rs368234815 polymorphism functionally associated with the outcome of HCV infection [9]. Firstly, we aimed to investigate whether IFNL4 rs368234815 is associated with spontaneous $\mathrm{HCV}$ clearance in ESRD patients on 
regular HD treatment. If so, whether genotyping of rs368234815 in HD subjects can be more useful as a predictor of spontaneous $\mathrm{HCV}$ resolution than other tested IFNL3/IFNL4 polymorphisms (near IFNL3 rs12980275, IFNL3 rs4803217, IFNL4 rs12979860, near IFNL4 rs8099917). We also planned to check whether an analysis of haplotypes of tested IFNL3/IFNL4 SNPs could be useful in predicting $\mathrm{HCV}$ infection outcome in HD patients. Additionally, a retrospective survival analysis was performed concerning IFNL4 rs368234815 polymorphism. For a better understanding of genetic mechanisms underlying differences in analysed phenotypes possible attributed to IFNL (spontaneous $\mathrm{HCV}$ clearance, survival), we used in silico methods for prediction of alterations in transcription factor (TF) binding sites (TFBS) caused by the tested polymorphisms.

\section{Patients and methods Patients}

The study included $161 \mathrm{HD}$ subjects with persistently positive anti-HCV antibodies. They were enrolled between January 2009 and November 2018 in the Wielkopolska region of Poland. The same patients were also tested in this study for near IFNL3 rs12980275, IFNL3 rs4803217, IFNL4 rs12979860, and near IFNL4 rs8099917. Some of them were included in our previous studies indicating associations of these SNPs with spontaneous HCV clearance in HD subjects $[24,26]$. We used the current data of rs12980275, rs4803217, rs12979860, and rs8099917 to compare the predictability of spontaneous HCV clearance using the newly tested rs368234815 and previously established genetic markers of $\mathrm{HCV}$ resolution.

Enrolled patients were never treated with anti-HCV medications. Among them, 68 (42.2\%) spontaneously resolved HCV infection, whereas 93 (57.8\%) were persistently HCV RNA positive.

Eighty (49.7\%) HD subjects showed positive antibodies against core antigen (anti-HBc) of hepatitis B virus (HBV); 10 (6.2\%) HD individuals presented surface HBV antigen (HBsAg) positivity; 7 (4.3\%) patients were persistently HBV DNA positive. All HD patients tested negative for antibodies to the human immunodeficiency virus (anti-HIV-1/HIV-2).

We obtained demographic, clinical, and baseline laboratory data of HD patients from physicians of HD facilities.

\section{Survival studies}

All anti-HCV positive patients genotyped for IFNL4 rs368234815 were included in the retrospective longitudinal survival study. In this group, we analysed survival probability from the onset of renal replacement therapy
(RRT) to the last data collection (1st - 10th November 2020) concerning IFNL4 rs368234815 genotypes.

\section{Genotyping}

Chromosomal localization of tested IFNL3 and IFNL4 polymorphisms is shown in Supplementary Fig. 1A. of the Additional file 1.

IFNL4 rs368234815 polymorphism (TT/TT, $\Delta \mathrm{G} / \mathrm{TT}$, $\Delta \mathrm{G} / \Delta \mathrm{G})$ was genotyped by a polymerase chain reactionrestriction fragment length polymorphism (PCR-RFLP) method, as recently described by Pouryasin et al. [29]. Genotyping of rs4803217, rs12980275, rs8099917, and rs12979860 polymorphisms was carried out by a highresolution melting curve analysis (HRM) as described in our previous studies [24, 26]. Supplementary Table 1 in the Additional file 1 shows conditions for identifying polymorphisms genotyped by PCR-RFLP or HRM.

For quality control, approximately $10 \%$ of the randomly chosen samples were re-genotyped using the same genotyping method; the concordance rate was 100\%. Among 161 tested samples, two (1.2\%) failed the genotyping of rs12980275 and rs4803217 each, four $(2.5 \%)$ - rs12979860, and one (0.6\%) - rs8099917. We excluded samples that failed the genotyping from statistical analyses.

\section{Prediction of transcription factor binding sites}

Potential regulatory impacts of the rs4803217, rs12980275, rs8099917, rs12979860, and rs368234815 through modifications of the TFBS motifs were assessed with the experimental ENCODE TFBS ChIP-seq data [30] and in silico prediction of DNA-binding sites collected in HOCOMOCO version 9 [31], JASPAR CORE version 5.0 ALPHA 2016 [32], and CIS-BP version 1.02 [33] databases with FIMO software version 4.11.1 [34].

We performed the computational analysis on the GenBank DNA sequences (contig NT_011109.17) [35] adjacent to SNP positions. FASTA sequences, one per each SNP allele, were used as an input for the FIMO. To minimize false rates, we calculated the background file directly from input sequences with MEME-suit fastaget-Markov script.

We analysed results via a self-developed Python script to find locations of ENCODE ChIP-seq validated TFBS and FIMO predicted motif BS overlapping SNP positions. A $p$-value $<0.0005$ and $q$-value $<0.05$ were selected as the cut-off values for reliable predictions. Motifs matched in both orientations were also analysed concerning perfect reverse complement forming, thus increasing the true positive match probability. We identified TF annotation information from the SwissProt database [36] and filtered statistically significant differentially bound hits of Homo sapiens motifs. 


\section{Statistical methods}

The results are presented as percentages for categorical variables or medians (range) for continuous variables because they were usually non-normally distributed as determined by the Shapiro-Wilk test.

We compared demographic, clinical, and laboratory data in anti-HCV positive HD subjects stratified by HCV RNA testing results. Continuous variables were compared using the Mann-Whitney test. The Chi-squared test or exact Fisher's test was used for comparison of categorical variables, as appropriate.

We analysed the Hardy-Weinberg equilibrium (HWE) to compare the observed genotype frequencies to the expected ones using the Chi-square test $(P>0.05$ with $\mathrm{df}=$ 1 for balance).

We tested polymorphisms for trends in association using Fisher's test if two groups were compared or the Cochran-Armitage test if three groups were compared $\left(\mathrm{P}_{\text {trend }}\right)$. Genotype $\left(\mathrm{P}_{\text {genotype }}\right)$ and allelic $\left(\mathrm{P}_{\text {allelic }}\right)$ distributions were compared between the tested groups using Pearson's Chi-squared test or Fisher's exact test, as appropriate.

Odds ratios (OR) and 95\% confidence intervals (CIs) for OR were calculated to quantify how strongly the presence or absence of the tested allele or genotype is associated with the presence or absence of selected phenotypes of HD patients. Pearson's Chi-squared test was used for statistical evaluation of OR. All probabilities were two-tailed. We applied logistic regression to assess the significance of the IFNL4 genotype, among other possible determinants of $\mathrm{HCV}$ clearance. A ROC curve was plotted to show the AUC as a measure of the accuracy of the model.

This study's statistical power was estimated by Quanto 1.2.4, under the "unmatched case-control" study design, with the present sample sizes and genetic effects that were observed in the study. All analyses were performed with a type I error rate of 0.05 .

The survival studies were retrospectively performed from each patient's individual RRT onset (from 15 June 1983 to 27 July 2018) to each patient's outcome data (1st - 10th November 2020). Patients who underwent renal transplantation were analysed if they returned to haemodialysis treatment. All-cause, cardiovascular, infection-related, and neoplasm-related reasons for death were analysed. These analyses were also performed using dominant, recessive, and additive models of inheritance. Due to a relatively small number of $\mathrm{HCV}$ exposed patients, this analysis was planned as a preliminary one. The Kaplan-Meier method with the log-rank test was solely used to estimate differences in the cumulative proportion surviving, characterizing the genotype groups in each inheritance model.
Statistical analyses of the data mentioned above were performed using Statistica version 12 (Stat Soft, Inc., Tulsa, OK, USA). P-values less than 0.05 were considered significant. However, a Bonferroni correction was used for significance in detailed association analyses involving rs368234815 because such associations were not previously evaluated in HD patients.

Pair-wise LD between IFNL3 and IFNL4 polymorphisms was computed as both $\mathrm{D}^{\prime}$ and $\mathrm{r}^{2}$ using the genotype data from the tested sample and the Haploview 4.2 software [37] (Supplementary Fig. 1B in the Additional file 1). Haplotypes were estimated using the mentioned Haploview 4.2 software (sliding windows method) and statistically analysed if their incidence in the examined group was at least $1 \%$. Statistical significance was assessed using the 1000-fold permutation test. Only Pvalues corrected by the test rules were considered significant.

\section{Results \\ Patients}

The characteristics of HD patients exposed to HCV are shown in Table 1. Patients showing HCV RNA positivity compared with HCV RNA negative subjects were younger at RRT onset, had longer RRT duration, and more frequent chronic glomerulonephritis as a cause of ESRD. Liver enzyme activities were higher in HCV RNA positive patients.

\section{IFNL4 rs368234815, other IFNL polymorphisms, and spontaneous $\mathrm{HCV}$ resolution}

In all tested groups, the observed genotype frequencies were in concordance with HWE (Supplementary Table 2 in the Additional file 1).

In HCV exposed HD patients, IFNL4 rs368234815 was significantly associated with spontaneous HCV elimination. The TT/TT genotype subjects benefited with a 2.6-fold higher frequency of spontaneous HCV clearance than patients harbouring the $\Delta G$ allele (Table 2). In the dominant model of inheritance, the association of rs368234815 with HCV infection outcome was similar to that documented for other tested IFNL3/IFNL4 polymorphisms. In the additive model, rs368234815 TT/TT was the strongest predictor of HCV clearance. All these analyses were performed with the sample power equal to or exceeding 93\% (Table 3).

\section{IFNL4 rs368234815 as a predictor of spontaneous HCV clearance among other clinical data}

With the TT/TT genotype of rs368234815, age at RRT onset, RRT duration, and chronic glomerulonephritis were chosen as possible explanatory variables for $\mathrm{HCV}$ spontaneously clearance. Among tested variables, only the TT/TT genotype remained a significant predictor of 
Table 1 Demographic, clinical, and laboratory data of 161 HD patients showing positive anti-HCV antibodies

\begin{tabular}{|c|c|c|c|}
\hline Parameter & $\begin{array}{l}\text { HCV RNA positive } \\
n=93\end{array}$ & $\begin{array}{l}\text { HCV RNA negative } \\
n=68\end{array}$ & $P$ value $^{t}$ \\
\hline Male gender & $48(51.6)$ & $35(51.5)$ & 0.986 \\
\hline Age at RRT onset, years & $45.8(8.7-79.5)$ & $53.5(14.1-85.9)$ & 0.004 \\
\hline Diabetic nephropathy & $17(18.3)$ & $17(25.0)$ & 0.302 \\
\hline Chronic glomerulonephritis & $31(33.3)$ & $11(16.2)$ & 0.014 \\
\hline Hypertensive nephropathy & $10(10.8)$ & $9(13.2)$ & 0.630 \\
\hline RRT duration, years & $13.4(0-32.0)$ & $7.0(0.2-33.2)$ & 0.0009 \\
\hline $\mathrm{BMI}, \mathrm{kg} / \mathrm{m}^{2}$ & $23.1(15.2-50.4)$ & $23.5(16.2-37.1)$ & 0.471 \\
\hline HBsAg positivity & $5(5.4)$ & $5(7.4)$ & $0.744^{\ddagger}$ \\
\hline Anti-HBC positivity & $48(51.6)$ & $32(47.1)$ & 0.568 \\
\hline Not generating anti-HBs & $16(17.2)$ & $17(25.0)$ & 0.226 \\
\hline Anti-HBs titre, IU/L & $199.5(0-8045)$ & $284.0(0-1100)$ & 0.889 \\
\hline ALT, IU/L & $24(2-195)$ & $12.4(3-63)$ & 0.00007 \\
\hline AST, IU/L & $23(8-152)$ & $15(8-46)$ & 0.00001 \\
\hline ALP, IU/L & $110(15-647.3)$ & $87.8(45-803.8)$ & 0.016 \\
\hline GGT, IU/L & $48.5(7-498)$ & $27(7-692)$ & 0.001 \\
\hline C-reactive protein, mg/L & $6.0(0.2-127)$ & $5.4(0.3-101)$ & 0.916 \\
\hline Albumin, g/dL & $3.8(1.9-4.7)$ & $4.0(2-4.9)$ & 0.074 \\
\hline
\end{tabular}

Results are presented as median and range (minimum-maximum) or the number of patients presenting the indicated parameter with the $\%$ of the total of tested patients shown in parentheses

Abbreviations: $A L P$ alkaline phosphatase, ALT alanine aminotransferase, AST aspartate aminotransferase, Anti-HBC antibodies against core antigen of hepatitis B virus, Anti-HCV antibodies against hepatitis C virus, BMI body mass index, GGT gamma-glutamyltransferase, $H B S A g$ surface antigen of hepatitis $B$ virus, $H C V$ RNA ribonucleic acid of hepatitis $C$ virus, $H D$ haemodialysis, $R R T$ renal replacement therapy

Conversion factors to SI units are as follows: for alanine aminotransferase $-1 \mathrm{IU} / \mathrm{L}=0.0167 \mu \mathrm{kat} / \mathrm{L}$, for albumin $-1 \mathrm{~g} / \mathrm{dL}=10 \mathrm{~g} / \mathrm{L}$, for alkaline phosphatase $-1 \mathrm{IU} /$ $\mathrm{L}=0.0167 \mu \mathrm{kat} / \mathrm{L}$, for aspartate aminotransferase $-1 \mathrm{IU} / \mathrm{L}=0.0167 \mu \mathrm{kat} / \mathrm{L}$, for C-reactive protein $-1 \mathrm{mg} / \mathrm{L}=9.524 \mathrm{nmol} / \mathrm{L}$, for gamma-glutamyltransferase $1 \mathrm{IU} / \mathrm{L}=0.0167 \mu \mathrm{kat} / \mathrm{L}$

+ Chi-squared test for qualitative variables and Mann-Whitney test for quantitative variables

FFisher's exact test

HCV resolution (OR 2.526, 95\% CI 1.274-5.009, $P=$ $0.008)$. The accuracy of the model in the receiver operating characteristic (ROC) curve analysis indicated the area under the curve (AUC) of 0.710 (Fig. 1).

\section{Linkage disequilibrium}

We examined LD between the rs12980275, rs4803217, rs12979860, rs368234815, and rs8099917 SNPs (Supplementary Fig. $1 \mathrm{~B}$ in the Additional file 1). IFNL4 rs368234815 was the most strongly associated with rs12979860 $\left(r^{2}=0.81\right)$; the weakest association was shown between this SNP and rs8099917 $\left(r^{2}=0.31\right)$.

\section{IFNL3 and IFNL4 haplotype analysis}

We analysed the haplotypes of IFNL3 and IFNL4 SNPs concerning the outcome of HCV infection.

Results including haplotypes of 2-4 SNPs are shown in Supplementary Table 3 in the Additional file 1. All

Table 2 IFNL4 rs368234815 polymorphic variants and HCV RNA positivity in HD patients exposed to HCV

\begin{tabular}{|c|c|c|c|}
\hline Genotypes, MAF & $\begin{array}{l}\text { HCV RNA positive patients }(n=93) \\
n, \% \text { of all }\end{array}$ & $\begin{array}{l}\text { HCV RNA negative patients }(n=68) \\
n, \% \text { of all }\end{array}$ & $\begin{array}{l}\text { Odds ratio }(95 \% \mathrm{Cl}) \\
P \text {-value }\end{array}$ \\
\hline \multicolumn{4}{|c|}{ IFNL4 rs368234815 $\left(n=161, \mathrm{P}_{\text {trend }}{ }^{\dagger}=0.0009, \mathrm{P}_{\text {genotype }}{ }^{\ddagger}=0.004\right)$} \\
\hline$\pi / T$ & $29(31.2)$ & $37(54.4)$ & Reference \\
\hline$\Pi / \Delta \mathrm{G}$ & $49(52.7)$ & $28(41.2)$ & $2.233(1.140-4.373), 0.02^{\S}$ \\
\hline$\Delta \mathrm{G} / \Delta \mathrm{G}$ & $15(16.1)$ & $3(4.4)$ & 6.379 (1.685-24.16), 0.003 \\
\hline$\Pi / \Delta \mathrm{G}+\Delta \mathrm{G} / \Delta \mathrm{G}$ vs $\Pi \pi / T$ & $64(68.8)$ & $31(45.6)$ & 2.634 (1.377-5.037), 0.003 \\
\hline$\Delta \mathrm{G} / \Delta \mathrm{G}$ vs $\Pi / \pi T+\Pi / \Delta \mathrm{G}$ & $15(16.1)$ & $3(4.4)$ & $4.167(1.156-15.02), 0.02^{\S}$ \\
\hline MAF & $(0.42)$ & $(0.25)$ & $2.215(1.364-3.597), 0.001$ \\
\hline
\end{tabular}

P for HWE: All: 0.527, HCV RNA positive: 0.451, HCV RNA negative: 0.419

Abbreviations: $H C V$ hepatitis C virus, IFNL4 - interferon- $\lambda 4$ gene, $H D$ haemodialysis, MAF minor allele frequency, RNA ribonucleic acid

${ }^{\dagger}$ - Cochran-Armitage trend Test; ${ }^{\ddagger}-$ Pearson's Chi-squared test; $\S-$ not significant after the Bonferroni correction $(P>0.007)$ 
Table 3 Associations of IFNL3/IFNL4 polymorphisms with spontaneous HCV clearance in HD patients exposed to HCV

\begin{tabular}{|c|c|c|c|c|c|c|c|c|c|c|c|c|c|c|}
\hline \multirow[t]{2}{*}{ Gene $^{\dagger}$} & \multirow[t]{2}{*}{ rs no. } & \multicolumn{3}{|c|}{ HCV RNA positive } & \multicolumn{3}{|c|}{ HCV RNA negative } & \multicolumn{3}{|c|}{$\begin{array}{l}\text { A difference in genotype/ } \\
\text { allele distribution between } \\
\text { HCV RNA positive and } \\
\text { HCV RNA negative }\end{array}$} & \multicolumn{2}{|c|}{$\begin{array}{l}\text { The probability } \\
\text { of spontaneous } \\
\text { HCV clearance in } \\
\text { the dominant } \\
\text { mode of } \\
\text { inheritance }\end{array}$} & \multicolumn{2}{|c|}{$\begin{array}{l}\text { The probability } \\
\text { of spontaneous } \\
\text { HCV clearance in } \\
\text { the additive } \\
\text { mode of } \\
\text { inheritance }\end{array}$} \\
\hline & & $\mathbf{n}$ & $\begin{array}{l}\text { Genotype } \\
\text { distribution, n } \\
\text { (frequency) }\end{array}$ & MAF & $\mathbf{n}$ & $\begin{array}{l}\text { Genotype } \\
\text { distribution, n } \\
\text { (frequency) }\end{array}$ & MAF & $\begin{array}{l}\text { P } \\
\text { trend" }\end{array}$ & $\begin{array}{l}\text { P } \\
\text { genotype }\end{array}$ & $\begin{array}{l}\mathrm{P} \\
\text { allelic }^{\Delta}\end{array}$ & $\begin{array}{l}\mathrm{OR}, \\
95 \% \\
\mathrm{Cl}\end{array}$ & $\begin{array}{l}P \text { value }{ }^{\Delta}, \\
\text { sample } \\
\text { power }\end{array}$ & $\begin{array}{l}\mathrm{OR} \\
95 \% \\
\mathrm{Cl}\end{array}$ & $\begin{array}{l}P \text { value }{ }^{\Delta}, \\
\text { sample } \\
\text { power }\end{array}$ \\
\hline IFNL3 & 12980275 & 91 & $\begin{array}{l}\text { AA } 25(27.5) \\
\text { AG } 48(52.7) \\
\text { GG } 18(19.8)\end{array}$ & 0.46 & 68 & $\begin{array}{l}\text { AA } 35(51.5) \\
\text { AG } 26(38.2) \\
\text { GG } 7(10.3)\end{array}$ & 0.29 & 0.003 & 0.007 & 0.002 & $\begin{array}{l}2.8 \\
1.45- \\
5.43\end{array}$ & $\begin{array}{l}0.002 \\
97 \%\end{array}$ & $\begin{array}{l}3.60 \\
1.31- \\
9.91\end{array}$ & $\begin{array}{l}0.011 \\
>99.9 \%\end{array}$ \\
\hline IFNL3 & 4803217 & 92 & $\begin{array}{l}\text { GG } 29(31.5) \\
\text { GT } 48(52.2) \\
\text { TT } 15(16.3)\end{array}$ & 0.42 & 67 & $\begin{array}{l}\text { GG } 36(53.7) \\
\text { GT } 27(40.3) \\
\text { TT } 4(6.0)\end{array}$ & 0.26 & 0.002 & 0.01 & 0.003 & $\begin{array}{l}2.52 \\
1.32- \\
4.84\end{array}$ & $\begin{array}{l}0.005 \\
95 \%\end{array}$ & $\begin{array}{l}4.66 \\
1.39- \\
15.56\end{array}$ & $\begin{array}{l}0.008 \\
>99.9 \%\end{array}$ \\
\hline IFNL4 & 12979860 & 90 & $\begin{array}{l}\text { CC } 29(32.2) \\
\text { CT } 45(50.0) \\
\text { TT } 16(17.8)\end{array}$ & 0.43 & 67 & $\begin{array}{l}\text { CC } 36(53.7) \\
\text { CT } 26(38.8) \\
\text { TT } 5(7.5)\end{array}$ & 0.27 & 0.004 & 0.015 & 0.004 & $\begin{array}{l}2.44 \\
1.27- \\
4.69\end{array}$ & $\begin{array}{l}0.007 \\
93 \%\end{array}$ & $\begin{array}{l}3.97 \\
1.30- \\
12.14\end{array}$ & $\begin{array}{l}0.012 \\
>99.9 \%\end{array}$ \\
\hline IFNL4 & 368234815 & 93 & $\begin{array}{l}T / T T 29(31.2) \\
T / \Delta G 49(52.7) \\
\Delta G / \Delta G 15(16.1)\end{array}$ & 0.42 & 68 & $\begin{array}{l}T T / T \operatorname{T} 37(54.4) \\
T T / \Delta \mathrm{G} 28(41.2) \\
\Delta \mathrm{G} / \Delta \mathrm{G} 3(4.4)\end{array}$ & 0.25 & 0.0009 & 0.004 & 0.001 & $\begin{array}{l}2.63 \\
1.38- \\
5.04\end{array}$ & $\begin{array}{l}0.003 \\
97 \%\end{array}$ & $\begin{array}{l}6.38 \\
1.69- \\
24.2\end{array}$ & $\begin{array}{l}0.003 \\
>99.9 \%\end{array}$ \\
\hline IFNL4 & 8099917 & 92 & $\begin{array}{l}\text { TT } 48(52.2) \\
\text { GT } 38(41.3) \\
\text { GG } 6(6.5)\end{array}$ & 0.27 & 68 & $\begin{array}{l}\text { TT } 51(75) \\
\text { GT } 17(25) \\
\text { GG } 0(0)\end{array}$ & 0.13 & 0.001 & $0.003^{\#}$ & 0.001 & $\begin{array}{l}2.75 \\
1.39- \\
5.45\end{array}$ & $\begin{array}{l}0.003 \\
98 \%\end{array}$ & $\begin{array}{l}13.8 \\
0.76- \\
251.6\end{array}$ & $\begin{array}{l}0.027^{\#} \\
>99.9 \%\end{array}$ \\
\hline
\end{tabular}

† - chromosomal localization of IFNL3 and IFNL4 genes towards the forward strand is shown

$\neq-$ genotypes with the variant alleles as reference

$\S$ - the variant homozygosity as reference

I - Cochran-Armitage Trend Test

$\Delta$ - Pearson's Chi-squared test

\# - Fisher's exact test

haplotypes composed exclusively of major alleles were significantly associated with spontaneous HCV clearance.

Data concerning the haplotypes of all five tested SNPs are presented in Table 4. If all haplotypes other than the tested one were pooled together and used as the reference, spontaneous HCV clearance was positively associated with the haplotype composed of major alleles of all five tested IFNL3/IFNL4 SNPs (OR 2.294, 95\% CI $1.412-3.727, P=0.0007)$. The haplotype, associated with a lower probability of spontaneous $\mathrm{HCV}$ resolution, was composed of variant alleles of all five tested polymorphisms (OR 0.380, 95\% CI 0.197-0.732, $P=0.003$ ). When the tested haplotype included both variant and major alleles of IFNL3 and IFNL4 SNPs, there was no significance in the outcome of HCV infection (Table 4 and Supplementary Table 3 in the Additional file 1).

\section{In silico analysis}

To study the potential regulatory impacts of the rs4803217, rs12980275, rs8099917, rs12979860, and rs368234815, we analysed the modifications of the TFBS motifs caused by these SNPs. Data of the in silico analysis are summarized in Table 5. Firstly, we used the public ENCODE TFBS ChIP-seq dataset from 187 TFs tested in 125 cell lines to find peaks overlapping SNP positions. We found no peaks overlapping positions of rs4803217 and rs12980275. ENCODE ChIP-seq peaks for the ZNF263, GATA1, POLR2A, and ARID3A TFs overlapped the position of the rs8099917. Positions of the rs12979860 and rs368234815 overlapped with the EZH2 ENCODE ChIP-seq peaks. In our in silico analysis, none of the predicted ENCODE ChIP-seq peaks for the TFBS overlapped positions of these SNPs directly. Therefore, they are not shown in Table 5.

The computational analysis revealed no direct differential motif binding for rs12980275 and rs8099917. Differentially bound transcription factors (TFs) were revealed for rs4803217 [HES2, DNA (cytosine-5)-methyltransferase 1 (DNMT1), Homeobox protein NKX3-2, POU domain, class 6, transcription factor 1 (POU6F1)], rs12979860 [E2F7, Oxysterols receptor LXR-alpha: Retinoid $\mathrm{X}$ receptor alpha (Nr1h3::Rxra), MAX Dimerization Protein (MGA), Oestrogen Related Receptor Alpha (ESRRA), T-box brain protein 1 (TBR1)], and rs368234815 (PLAG1 like zinc finger 1 identified also as M6422_1.02) (Table 5).

\section{Survival and IFNL4 rs368234815}

During the analysed period (an RRT duration), lasting in individual cases from 0.19 years to 34.0 years (median 11.2 years), we recorded 96 all-cause deaths of the examined HD patients. Cardiovascular, infection-related, neoplasm-related, and other reasons of deaths comprised $55.2 \%(n=53), 15.6 \%(n=15), 9.4 \%(n=9)$, and $19.8 \%$ 


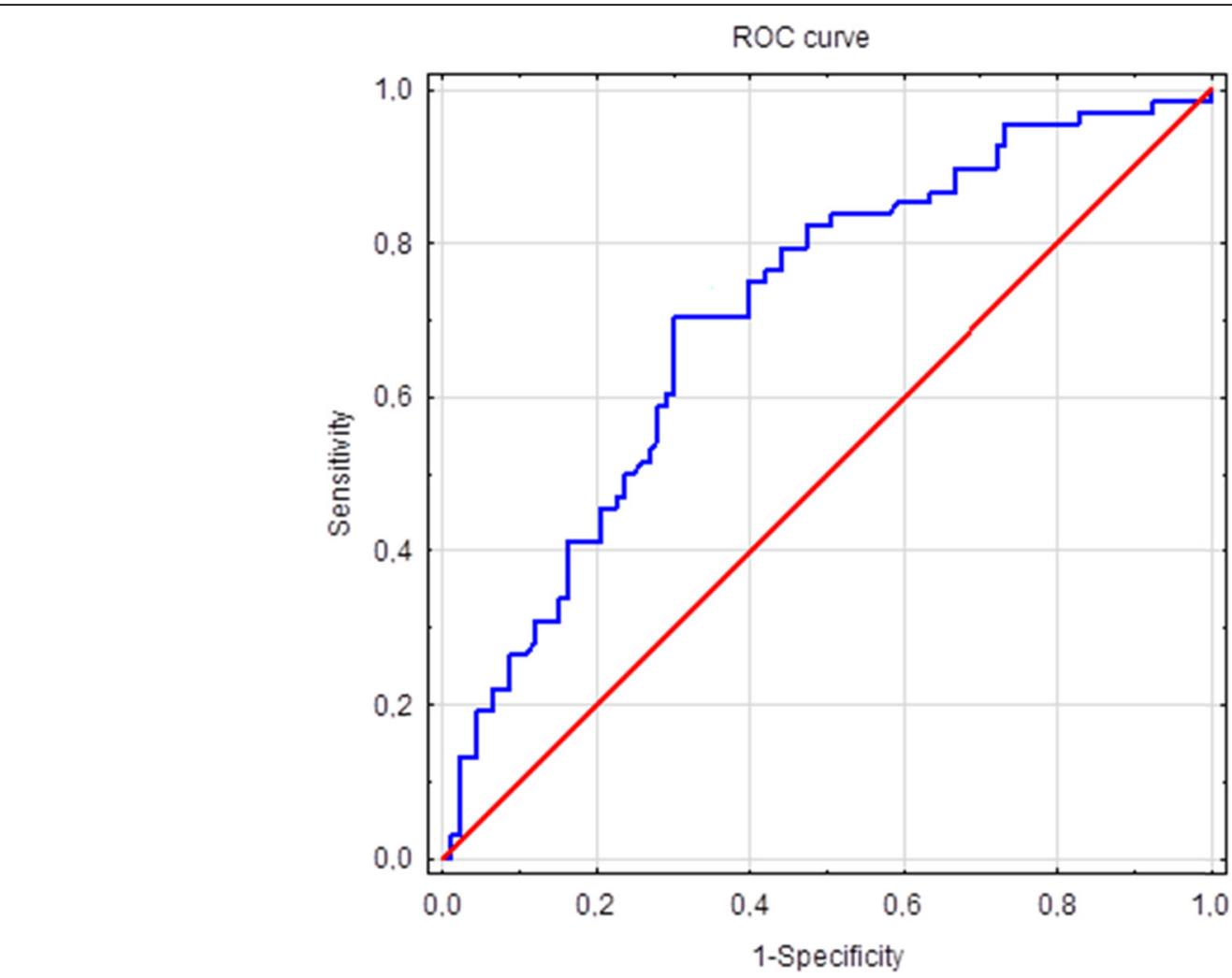

$\mathrm{AUC}=0.710$

Fig. 1 The area under the curve as a measure of the accuracy of the model created to predict spontaneous HCV clearance. A receiver operating characteristic (ROC) curve was plotted to show the area under the curve (AUC) as a measure of the accuracy of the model created for evaluation of selected explanatory variables of spontaneous HCV clearance. The model included the TT/TT genotype of rs368234815, age at RRT onset, RRT duration, and chronic glomerulonephritis. All these variables significantly differed HCV RNA positive and HCV RNA negative HD individuals (Table 1)

Table 4 Frequencies of IFNL3 and IFNL4 haplotypes concerning spontaneous HCV elimination (cases) and persistent HCV infection (controls)

\begin{tabular}{|c|c|c|c|c|c|c|c|c|}
\hline SNPs & Haplotype & $\begin{array}{l}\text { Haplotype } \\
\text { Frequencies }\end{array}$ & $\begin{array}{l}\text { Case, } \\
\text { Control } \\
\text { Frequencies }\end{array}$ & $\begin{array}{l}\text { Chi } \\
\text { Square }\end{array}$ & $\begin{array}{l}\text { P } \\
\text { Value }\end{array}$ & $\begin{array}{l}P_{\text {corr }} \\
\text { Value }^{\dagger}\end{array}$ & $\begin{array}{l}\text { OR }(95 \% \mathrm{Cl})^{\ddagger}, P \\
\text { Value }\end{array}$ & $\begin{array}{l}\text { OR }(95 \% \mathrm{Cl})^{\S}, \mathrm{P} \\
\text { Value }\end{array}$ \\
\hline \multirow[t]{6}{*}{$\begin{array}{l}\text { rs12980275_rs4803217_rs12979860_ } \\
\text { rs368234815_rs8099917 }\end{array}$} & $\begin{array}{l}A_{-} C_{-} C_{-} \\
T_{-}^{T}\end{array}$ & 0.562 & $0.667,0.485$ & 10.590 & 0.0011 & 0.0060 & $\begin{array}{l}2.294(1.412- \\
3.727), 0.0007\end{array}$ & Reference \\
\hline & $\mathrm{G}_{\bar{G}} \mathrm{~A}_{\overline{\mathrm{G}}} \mathrm{T}_{-}$ & 0.174 & $0.102,0.227$ & 8.543 & 0.0035 & 0.0190 & $\begin{array}{l}0.380(0.197- \\
0.732), 0.0030\end{array}$ & $\begin{array}{l}0.326(0.167- \\
0.638), 0.0008\end{array}$ \\
\hline & $\mathrm{G}_{\bar{G}} \mathrm{~A}_{-} \mathrm{T}^{\mathrm{T}}-$ & 0.121 & $0.110,0.130$ & 0.289 & 0.5909 & 1.0000 & $\begin{array}{l}0.819(0.411- \\
1.632), 0.5692\end{array}$ & $\begin{array}{l}0.611(0.301- \\
1.241), 0.1706\end{array}$ \\
\hline & $\begin{array}{l}\mathrm{G}_{-} C_{-} C_{-} \\
\mathrm{TT}_{-} \mathrm{T}\end{array}$ & 0.043 & $0.037,0.046$ & 0.164 & 0.6855 & 1.0000 & $\begin{array}{l}0.736(0.241- \\
2.253), 0.5901\end{array}$ & $\begin{array}{l}0.543(0.175- \\
1.685), 0.2847\end{array}$ \\
\hline & $\mathrm{A}_{\Delta \bar{G}_{-} \mathrm{A}_{\bar{T}}^{\mathrm{T}}-}$ & 0.020 & $0.008,0.028$ & 1.583 & 0.2083 & 0.7840 & $\begin{array}{l}0.263(0.030- \\
2.280), 0.1934\end{array}$ & $\begin{array}{l}0.196(0.022- \\
1.709), 0.1024\end{array}$ \\
\hline & $\mathrm{G}_{-}^{\mathrm{T}_{-}} \mathrm{A}_{-} \mathrm{T}_{-}$ & 0.016 & $0.015,0.016$ & 0.013 & 0.9081 & 1.0000 & $\begin{array}{l}0.894(0.147- \\
5.434), 0.9032\end{array}$ & $\begin{array}{l}0.652(0.106- \\
3.997), 0.6415\end{array}$ \\
\hline
\end{tabular}

${ }^{\dagger} P$-value calculated using the permutation test and a total of 1000 permutations

${ }^{\ddagger}$ All other haplotypes pooled together were used as the reference

${ }^{\S}$ The most common haplotype was used as the reference 
Table 5 Prediction of TFBS by the software FIMO for rs368234815, rs12980275, rs12979860, rs8099917, and rs4803217

\begin{tabular}{|c|c|c|c|c|c|}
\hline SNP/allele & Transcription factor & $\begin{array}{l}\text { Modification (in the presence of } \\
\text { the minor allele) }\end{array}$ & Strand & $\begin{array}{l}p \text {-value/q- } \\
\text { valuet }\end{array}$ & $\begin{array}{l}\text { Matched } \\
\text { sequence }\end{array}$ \\
\hline $\mathrm{rs} 368234815 / \Delta \mathrm{G}$ & PLAG1 like zinc finger 1 & Removed & $"+"$ & $\begin{array}{l}7.49 \mathrm{e}-05 / \\
0.0636\end{array}$ & CGGGGGGCCT \\
\hline rs12979860/ T & Transcription factor E2F7 & Removed & $"+"$ & $\begin{array}{l}2.49 \mathrm{e}-05 / \\
0.0288\end{array}$ & $\begin{array}{l}\text { GAAGGCGCGA } \\
\text { ACC }\end{array}$ \\
\hline rs12979860/ T & $\begin{array}{l}\text { Oxysterols receptor LXR-alpha: Retinoid X recep- } \\
\text { tor alpha (Nr1h3::Rxra) }\end{array}$ & Added & $"+"$ & $\begin{array}{l}6.03 e-05 / \\
0.0423\end{array}$ & $\begin{array}{l}\text { TGAACCAGGG } \\
\text { TTGAATTGC }\end{array}$ \\
\hline rs12979860/T & Oestrogen Related Receptor Alpha (ESRRA) & Removed & - & $\begin{array}{l}4.71 \mathrm{e}-05 / \\
0.0498\end{array}$ & TCAGGGTCAAT \\
\hline rs12979860/ T & MAX Dimerization Protein (MGA) & Added & $"+"$ & $\begin{array}{l}9.32 \mathrm{e}-05 / \\
0.00347\end{array}$ & AGGCGTGA \\
\hline rs12979860/ T & T-box brain protein 1 (TBR1) & Added & $"+"$ & $\begin{array}{l}5.29 \mathrm{e}-05 / \\
0.0495\end{array}$ & AGGCGTGAAC \\
\hline rs4803217/ A & Transcription factor HES-2 & Added & $"+"$ & $\begin{array}{l}7.76 \mathrm{e}-05 / \\
0.00974\end{array}$ & TTAAGACAAGTGG \\
\hline rs4803217/ A & DNA (cytosine-5)-methyltransferase 1 (DNMT1) & Removed & $"+"$ & $\begin{array}{l}9.7 e-06 / \\
0.0499\end{array}$ & CCCCGCTGGC \\
\hline rs4803217/ A & Homeobox protein NKX3-2 & Removed & $"+"$ & $\begin{array}{l}7.51 \mathrm{e}-05 / \\
0.0107\end{array}$ & AGCCAAGTGGC \\
\hline rs4803217/ A & $\begin{array}{l}\text { POU domain, class } 6 \text {, transcription factor } 1 \\
\text { (POU6F1) }\end{array}$ & Removed & $"+"$ & $\begin{array}{l}4.41 \mathrm{e}-05 / \\
0.0279\end{array}$ & AATAAATTAAGCC \\
\hline
\end{tabular}

Abbreviation: TFBS transcription factor binding sites

The table contains only statistically significant in silico predicted differentially bound transcription factors

$\dagger-$ The calculated log-odds scores were converted with a dynamic programming algorithm into $p$-values by FIMO software. The $p$-values for each motif occurrence were converted to $q$-values following Benjamini and Hochberg [38]

$(n=19)$ of all deceased patients, respectively. There were no significant differences in overall survival probability and specific reasons for death, but the neoplasm-related cause (log-rank $P=0.005$ in the recessive inheritance mode for rs368234815, Supplementary Fig. 2 in the Additional file 1).

To further explore a possible association between the IFNL4 rs368234815 $\Delta \mathrm{G} / \Delta \mathrm{G}$ genotype and mortality due to neoplasm, we genotyped not HCV-exposed HD patients who died from cancer in the analysed period, and their DNA samples were stored. We gathered 82 samples $(P$-value for HWE concerning rs368234815 SNP = $0.803)$. In this group, the $\Delta \mathrm{G} / \Delta \mathrm{G}$ genotype was not associated with mortality due to cancer disease (log-rank $P>0.05$ for all three inheritance models).

\section{Discussion}

IFNL4 rs368234815 polymorphism is recognized as the most potent predictor of HCV infection outcome in the general population [18]. To our knowledge, this paper, for the first time, describes associations between IFNL4 rs368234815 polymorphism and spontaneous HCV clearance in HD patients who substantially differ from the general population due to persistent uremic status and altered immune competence [39]. In this study, we applied the PCR_RFLP method for genotyping of rs368234815 polymorphism, which was recently described by Pouryasin et al. [29]. Among Iranian non- uremic patients with chronic HCV infection tested with this method, the rs368234815 $\Delta \mathrm{G} / \Delta \mathrm{G}$ frequency was 17.3\% [29]. Caucasian HD patients of Polish origin with persistently positive testing for HCV RNA revealed a similar frequency of the $\Delta \mathrm{G} / \Delta \mathrm{G}$ genotype (16.1\%).

Similarly, as in non-uremic subjects $[14,15]$, rs368234815 was associated with spontaneous $\mathrm{HCV}$ clearance also in HD patients. On the same group of anti-HCV positive HD patients, we were able to show that major homozygosity in rs368234815 (TT/TT) similarly predicts spontaneous HCV clearance in the dominant model of inheritance as other tested IFNL3/IFNL4 polymorphisms already associated with $\mathrm{HCV}$ clearance in HD subjects. All tested IFNL polymorphisms (including rs368234815) indicated a 2.4-2.8-fold higher frequency of spontaneous HCV clearance in HD patients characterized by the major homozygosity in analysed polymorphisms.

The usefulness of the IFNL4 rs368234815 TT/TT genotype in the predictability of spontaneous $\mathrm{HCV}$ clearance was superior to other tested IFNL polymorphisms only in the additive inheritance model. In nonuremic subjects, the rs368234815 TT/TT genotype indicated 3.6-fold (Swiss Caucasians [15]) - 12-fold (American white women [14]) higher frequency of spontaneous $\mathrm{HCV}$ clearance compared with the $\Delta \mathrm{G} / \Delta \mathrm{G}$ genotype. In HD patients, the TT/TT genotype predicted a 6.4-fold higher probability of spontaneous $\mathrm{HCV}$ clearance. 
Therefore, uremic conditions do not seem to influence substantially IFNL4 rs368234815 expression concerning spontaneous HCV resolution. Additionally, an identification of the homozygosity in the variant $\Delta G$ allele of rs368234815 in HD subjects means a more potent prediction of persistent $\mathrm{HCV}$ infection that it is observed in the case of the variant homozygosity of other tested IFNL3/IFNL4 polymorphisms.

A question was raised whether the haplotype of unfavourable rs368234815 $\Delta \mathrm{G}$ allele and favourable major allele of any other IFNL3/IFNL4 SNPs could be associated with more frequent spontaneous $\mathrm{HCV}$ clearance. Data of O'Brien et al. [18] excluded such a possibility for the haplotype of a favourable major allele of IFNL3 rs4803217 [40, 41] and the unfavourable IFNL4 rs368234815 $\Delta \mathrm{G}$ allele concerning a day 28 anti-HCV response in African American individuals. A recent study by Vergara et al. [42] demonstrated in the European ancestry group that subjects with the haplotype rs368234815 GG_rs4803221C were 1.7 times more likely to clear HCV than individuals showing rs368234815 $\Delta \mathrm{G}_{-}$ rs4803221G haplotype. Also, the haplotype rs368234815 $\Delta$ G_rs8099917T was associated with a 1.6 times higher frequency of $\mathrm{HCV}$ resolution compared to rs368234815 $\Delta$ G_rs8099917G haplotype. There were no differences in association analysis of these two haplotypes concerning spontaneous HCV clearance in African ancestry [42]. In the examined European HD patients, only haplotypes containing exclusively major alleles of tested IFNL3/IFNL4 SNPs were associated with spontaneous HCV resolution. In HD patients, similarly to in African Americans [42], there were no significant differences in spontaneous HCV clearance frequency if haplotype was composed of rs368234815 $\Delta \mathrm{G}$ and major versus variant allele of tested IFNL3/IFNL4 SNPs (Supplementary Table 4 in the Additional file 1). However, a relatively small group of the examined patients could participate in a lack of significance. It has to be noted that novel SNPs were recently identified in the IFNL region of which rs4803221 (and already known rs8099917) appear contributors in a primary signal of association represented by IFNL4 rs368234815 SNP [42].

Spontaneous HCV elimination is associated with the induction of virus-specific $\mathrm{CD}^{+}$and $\mathrm{CD}^{+} \mathrm{T}$ cell responses and, to a lesser extent, with the generation of neutralising antibodies targeting the HVR1 region of HCV envelope glycoprotein 2 [43]. The rs368234815 impact on HCV infection outcome is still investigated. The IFNL4 rs368234815 TT allele, which promotes spontaneous HCV clearance, is associated with the expression of the transcript JN806227. The latter generates a prematurely terminated IFN- $\lambda 4$ protein with a lack of activity $[9,10]$. The IFNL4 $\Delta G$ allele transcript produces fulllength IFN- $\lambda 4$, of which IFN- $\lambda 4$-70Pro is more active, while IFN- $\lambda 4$-70Ser shows diminished activity. This difference depends on nonsynonymous variant IFNL4 rs117648444 A/G (Pro70Ser) in exon 2. IFNL4 haplotype rs368234815 $\Delta$ G_rs117648444G produces a more active IFN- $\lambda 4$-70Pro and is captured by rs 8099917 variant (G) allele, haplotype rs368234815TT_rs117648444G corresponds to lack of active IFN- $\lambda 4$, and rs368234815 $\Delta \mathrm{G}_{-}$ rs117648444A generates a less active IFN- $\lambda 4-70$ Ser. Both latter haplotypes are tagged by the rs8099917 $\mathrm{T}$ allele [9, 44]. It is suggested that one of the possible mechanisms, by which primarily intracellular IFN $\lambda 4$ deteriorates $\mathrm{HCV}$ elimination, is up-regulation of IFN- $\lambda$ R 1 what impedes receptor binding of the other members of the IFN- $\lambda$ family [45]. Recent analyses [46] have shown that IFNL4 rs12979860, being a marker for rs368234815, is strongly associated with the HCV proteome's amino acid variants. Like that concerning leucine at position 2224 of NS5A in HCV genotype $1 \mathrm{~b}$ in patients with the rs12979860 CC genotype, some of these associations correspond to the pre-treatment viral load. The rs12979860 variant (T) allele correlated with lower pretreatment viral load for all $\mathrm{HCV}$ genotypes, while the rs12979860 CC genotype was associated with higher mean viral load. Therefore, the difference in viral load could be partially related to changes in viral amino acids associating with the presence or absence of IFN- $\lambda 4$ [46]. It has to be noted that the rs12979860 CC genotype was simultaneously associated with spontaneous HCV clearance and higher viral load. The latter was inversely [47] or positively [48] correlated with spontaneous HCV elimination in clinical studies. The coincidence of rs12979860, viral load, and HCV eradication needs exploration in further investigations.

We identified that minor alleles of the rs368234815, rs12979860, and rs4803217 could cause statistically significant changes in TFBS. Therefore, the individual or combined effects of those changes may contribute to the differential IFNL3 and IFNL4 expression. As IFNL3/ IFNL4 polymorphisms are well-established predictors of $\mathrm{HCV}$ clearance, removal or addition of the host TFBS in the presence of the minor alleles of tested polymorphisms might be at least a partial explanation of $\mathrm{HCV}$ persistence in the IFNL3/IFNL4 minor allele bearers. Our computational analysis provides a list of candidate differentially bound TFBS in tested variants. The experimental ChIP-seq study could be applied to verify their impact exerted by the minor alleles. The following example shows how critical is the need for such verification. In silico analysis revealed that the host TFBS for DNA DNMT1 is removed in the IFNL3 rs4803217 minor allele bearers who are predisposed to persistent HCV infection ([18, 40, 41], this study). However, CpG islands for DNMT1-induced DNA methylation were not shown in the interferon- $\lambda$ genetic region [49], so 
removing TFBS for DNMT1 may have no clinical relevance concerning HCV clearance. Nonetheless, the proposed putative mechanistic hypothesis describing the effects of the studied SNPs on TFBS serves as an exploratory analysis based on computational studies. Moreover, the public reference dataset is an approximation of the cellular and tissue states in studied samples.

In our study, the IFNL4 rs368234815 $\Delta \mathrm{G} / \Delta \mathrm{G}$ genotype appeared to be associated with cancer mortality in HCVexposed HD patients. We consider this finding as a preliminary one due to a small number of HD patients who died from cancers in this group. Additionally, such a survival analysis in the examined not HCV-exposed subjects did not reveal any relationship between neoplasmrelated mortality and IFNL4 rs368234815 SNP. On the other hand, our data are following the evidence demonstrating reduced survival in rs368234815 $\Delta G / \Delta G$ genotype or rs12980275 GG genotype (corresponds to rs368234815 $\Delta \mathrm{G} / \Delta \mathrm{G}$ genotype) subjects with cancers $[50,51]$.

IFN- $\lambda$ has a dual role in cancer. Direct antitumor effects of IFN- $\lambda$ include inhibition of cell proliferation, promotion of cell apoptosis, and cell cycle arrest. Indirect antitumor effects of IFN- $\lambda$ include immune cell activation and angiogenesis inhibition. However, new evidence indicates that IFN- $\lambda$ can also promote oncogenesis [52]. IFNL polymorphisms may differentiate their role in cancer antitumor effects or oncogenesis. Our in silico analyses demonstrated that neoplasm-related mortality might be due to the removal of TFBS for PLAGL1 zinc finger 1 protein, which is associated with antiproliferative activities and tumour suppression. PLAGL1 gene is often deleted or methylated and silenced in cancer cells [53]. This exciting aspect needs further elaboration.

\section{Conclusions}

1. In HD patients, the association of IFNL4 rs368234815 with the spontaneous HCV clearance is more potent than that documented for other IFNL3/IFNL4 polymorphisms (IFNL3 rs12980275, IFNL3 rs4803217, IFNL4 rs12979860, and near IFNL4 rs8099917) only in the additive mode of inheritance.

2. An identification of the rs368234815 $\Delta \mathrm{G}$ allele homozygosity means a more potent prediction of persistent $\mathrm{HCV}$ infection in HD subjects than observed in the case of the variant homozygosity of other tested IFNL3/IFNL4 polymorphisms.

3. Removal of PLAGL1 TFBS in subjects harbouring the rs368234815 $\Delta \mathrm{G}$ allele may contribute to cancer susceptibility.
4. The association of rs368234815 with cancer-related mortality needs further studies in HCV-exposed HD subjects.

\section{Supplementary Information}

The online version contains supplementary material available at https://doi. org/10.1186/s12879-021-05777-6.

Additional file 1: Supplementary data for polymorphism rs368234815 of interferon lambda 4 gene and spontaneous clearance of hepatitis C virus in haemodialysis patients. Supplementary material contains genotyping conditions for identifying tested polymorphisms, results of HardyWeinberg equilibrium, and haplotype analysis. Figures show chromosomal localization of tested IFNL3/IFNL4 polymorphisms and the Kaplan-Meier cumulative proportion surviving for haemodialysis patients with neoplasms.

\section{Abbreviations}

AUC: Area under the curve; Cl: Confidence interval; DNA: Deoxyribonucleic acid; DNMT1: DNA (cytosine-5)-methyltransferase 1; ESRD: End-stage renal disease; ESRRA: Estrogen Related Receptor Alpha; HCV: Hepatitis C virus; HD: Hemodialysis; HRM: High-resolution melting curve analysis; HWE: HardyWeinberg equilibrium; IFNL: Interferon- $\lambda$ genetic region; IFNL3: Interferon- $\lambda 3$ gene; IFNL4: Interferon- $\lambda 4$ gene; IFN- $\lambda$ : Interferon- $\lambda$; INF- $\lambda$ R1: Interferon- $\lambda$ receptor 1; ISG: Interferon-stimulated genes; ISRE: Interferon-stimulated response element; JAK: Janus activated kinase; LD: Linkage disequilibrium; MGA: MAX Dimerization Protein; mRNA: messenger ribonucleic acid; Nr1h3::Rxra: Oxysterols receptor LXR-alpha: Retinoid X receptor alpha; OR: odds ratio; PCR-RFLP: Polymerase chain reaction-restriction fragment length polymorphism; POU6F1: POU domain, class 6, transcription factor 1; ROC: Receiver operating characteristic; RNA: Ribonucleic acid; RRT: Renal replacement therapy; SNP: Single nucleotide polymorphism; STAT: Signal transducer and activator of transcription; TBR1: T-box brain protein 1; TF: Transcription factor; TFBS: Transcription factor binding sites

\section{Acknowledgements}

Selected results of this study have previously been presented at 56th ERAEDTA CONGRESS. Budapest, Hungary, June 13th-16th, 2019. Abstr. FP679. Nephrol. Dial. Transplant. 2019:34(suppl)1, i278-i279.

\section{Authors' contributions}

AEG conceived the study, designed the research, was involved in the data collection, analysed the data, wrote the manuscript, and participated in funding for the project. MKŚ was involved in the data collection and analysed the data. WM collected the patients' data. AM was responsible for the genotyping and haplotype analysis. IS and MF did in silico studies. PPJ participated in funding for the project. All authors edited and approved the final version of the manuscript.

\section{Funding}

This work was supported by the Poznan University of Medical Sciences, Poznań, Poland [grant numbers 502-01-02225363-03679, 502-01-0112418207474]. The study sponsor was not involved in the study design; in the collection, analysis, and interpretation of data; in the report's writing; and in the decision to submit the manuscript for publication.

\section{Availability of data and materials}

The datasets used and analysed during the current study are available from the corresponding author on reasonable request.

\section{Ethics approval and consent to participate}

The study design was approved by the Institutional Review Board of Poznan University of Medical Sciences, Poland. Written informed consent was obtained from all HD patients included in the study or their parents, as appropriate. All methods were performed under the Helsinki Declaration's ethical standards (1964, amended most recently in 2008), which was created by the World Medical Association. 


\section{Consent for publication}

Not applicable.

\section{Competing interests}

The authors declare that they have no competing interests.

\section{Author details}

'Department of Nephrology, Transplantology and Internal Diseases, Poznan University of Medical Sciences, Przybyszewskiego 49, 60-355 Poznań, Poland. ${ }^{2}$ Department of Biochemistry and Molecular Biology, Poznan University of Medical Sciences, Święcickiego 6, 60-781 Poznań, Poland. ${ }^{3}$ Fresenius Nephrocare Polska, Krzywa 13, 60-118 Poznań, Poland. ${ }^{4}$ Institute of Bioorganic Chemistry, Polish Academy of Sciences, Poznań, Poland.

\section{Received: 4 December 2019 Accepted: 7 January 2021}

Published online: 22 January 2021

\section{References}

1. Kotenko SV, Gallagher G, Baurin W, et al. IFN-lambdas mediate antiviral protection through a distinct class II cytokine receptor complex. Nat Immunol. 2003:4:69-77.

2. Sheppard P, Kindsvogel W, Xu W, et al. IL-28, IL-29 and their class II cytokine receptor IL-28R. Nat Immunol. 2003;4:63-8.

3. Lu YF, Mauger DM, Goldstein DB, Urban TJ, Weeks KM, Bradrick SS. IFNL3 mRNA structure is remodeled by a functional non-coding polymorphism associated with hepatitis C virus clearance. Sci Rep. 2015;5:16037.

4. Tanaka Y, Nishida N, Sugiyama M, et al. Genome-wide association of IL28B with response to pegylated interferon-alpha and ribavirin therapy for chronic hepatitis C. Nat Genet. 2009;41:1105-9.

5. Fukuhara T, Taketomi A, Motomura T, et al. Variants in IL28B in liver recipients and donors correlate with response to peg-interferon and ribavirin therapy for recurrent hepatitis C. Gastroenterology. 2010;139:157785.

6. Thomas $\mathrm{DL}$, Thio $\mathrm{CL}$, Martin MP, et al. Genetic variation in $\mathrm{L} 28 \mathrm{~B}$ and spontaneous clearance of hepatitis C virus. Nature. 2009;461:798-801.

7. Rauch A, Kutalik Z, Descombes P, et al. Swiss Hepatitis C Cohort Study; Swiss HIV Cohort Study. Genetic variation in IL28B is associated with chronic hepatitis $C$ and treatment failure: a genome-wide association study. Gastroenterology. 2010;138:1338-45.

8. Ito K, Higami K, Masaki N, et al. The rs8099917 polymorphism, when determined by a suitable genotyping method, is a better predictor for response to pegylated alpha interferon/ribavirin therapy in Japanese patients than other single nucleotide polymorphisms associated with interleukin-28B. J Clin Microbiol. 2011;49:1853-60.

9. Prokunina-Olsson L, Muchmore B, Tang W, et al. A variant upstream of IFNL3 (IL28B) creating a new interferon gene IFNL4 is associated with impaired clearance of hepatitis C virus. Nat Genet. 2013:45:164-71.

10. Murakawa M, Asahina $Y$, Nakagawa $M$, et al. Impaired induction of interleukin 28B and expression of interferon $\lambda 4$ associated with nonresponse to interferon-based therapy in chronic hepatitis $C$. J Gastroenterol Hepatol. 2015;30:1075-84.

11. Ferraris $P$, Chandra PK, Panigrahi $R$, et al. Cellular mechanism for impaired hepatitis $C$ virus clearance by interferon associated with IFNL3 gene polymorphisms relates to intrahepatic interferon- $\lambda$ expression. Am J Pathol. 2016;186:938-51.

12. Price $A A$, Tedesco D, Prasad MR, et al. Prolonged activation of innate antiviral gene signature after childbirth is determined by IFNL3 genotype. Proc Natl Acad Sci U S A. 2016:113:10678-83.

13. Keshvari M, Alavian SM, Behnava B, Pouryasin A, Sharafi $H$. The interferon lambda 4 rs368234815 predicts treatment response to pegylated-interferon alpha and ribavirin in hemophilic patients with chronic hepatitis C. J Res Med Sci. 2016:21:72.

14. Aka PV, Kuniholm MH, Pfeiffer RM, et al. Association of the IFNL4- $\Delta$ G allele with impaired spontaneous clearance of hepatitis C virus. J Infect Dis. 2014; 209:350-4.

15. Bibert S, Roger T, Calandra T, et al. Swiss hepatitis C cohort study. IL28B expression depends on a novel TT/-G polymorphism which improves HCV clearance prediction. J Exp Med. 2013;210:1109-16.

16. Franco S, Aparicio E, Parera M, Clotet B, Tural C, Martinez MA. IFNL4 ss469415590 variant is a better predictor than rs 12979860 of pegylated interferon-alpha/ribavirin therapy failure in hepatitis C virus/HIV-1 coinfected patients. AIDS. 2014;28:133-6.

17. Rugwizangoga B, Andersson ME, Kabayiza JC, et al. IFNL4 genotypes predict clearance of RNA viruses in Rwandan children with upper respiratory tract infections. Front Cell Infect Microbiol. 2019;9:340.

18. O'Brien TR, Pfeiffer RM, Paquin A, et al. Comparison of functional variants in IFNL4 and IFNL3 for association with HCV clearance. J Hepatol. 2015;63:1103-10.

19. Suppiah V, Moldovan M, Ahlenstiel G, et al. IL28B is associated with response to chronic hepatitis $C$ interferon-alpha and ribavirin therapy. Nat Genet. 2009;41:1100-4

20. Xie X, Zhang L, Chen YZ. Association between IFNL4 rs368234815 polymorphism and sustained virological response in chronic hepatitis C patients undergoing PEGylated interferon/ribavirin therapy: a meta-analysis. Hum Immunol. 2016;77:609-15.

21. Meissner EG, Bon D, Prokunina-Olsson L, et al. IFNL4- $\Delta$ G genotype is associated with slower viral clearance in hepatitis C, genotype-1 patients treated with sofosbuvir and ribavirin. J Infect Dis. 2014:209(11):1700-4.

22. Sung PS, Shin EC. Interferon response in hepatitis $C$ virus-infected hepatocytes: issues to consider in the era of direct-acting antivirals. Int Mol Sci. 2020;21(7):2583.

23. Zedan HE, Talaat RM, Ammar AAA, Sakr MA. Interferon-lambda 4 gene polymorphisms predict treatment response in Egyptian HCV genotype 4 patients exposed to radiation. Egypt J Hosp Med. 2019;77(1):4748-53.

24. Grzegorzewska AE, Jodłowska E, Mostowska A, Jagodziński P. Effect of interferon $\lambda 3$ gene polymorphisms, rs8099917 and rs12979860, on response to hepatitis $B$ virus vaccination and hepatitis B or C virus infections among hemodialysis patients. Pol Arch Med Wewn. 2015;125:894-902.

25. Dzekova-Vidimliski P, Nikolov IG, Matevska-Geshkovska N, Mena S, Rostaing L, Dimovski A, Sikole A. Single nucleotide polymorphisms near IL28B gene and response to treatment of chronic hepatitis $C$ in hemodialysis patients. Ren Fail. 2015;37:1180-4.

26. Grzegorzewska AE, Winnicka H, Warchoł W, Marcinkowski W, Mostowska A, Jagodziński PP. Effects of interferon- $\lambda 3$ gene polymorphic variants in response to HBV vaccination and outcome of HBV and HCV infections in hemodialysis patients. In: hemodialysis abstracts from the 39th annual Dialysis conference (Dallas). Hemodial Int. 2019;23(1):A17-8.

27. Yu ML. Dai CY, Huang CF, et al; FORMOSA-LIKE group. High hepatitis B virus surface antigen levels and favorable interleukin 28B genotype predict spontaneous hepatitis C virus clearance in uremic patients. J Hepatol. 2014;60:253-9.

28. Rukov JL, Gravesen E, Mace ML, et al. Effect of chronic uremia on the transcriptional profile of the calcified aorta analyzed by RNA-sequencing. Am J Physiol Renal Physiol. 2016:310:F477-91.

29. Pouryasin M, Sharafi H, Behnava B, Alavian SM, Keshvari M, Pouryasin A. A simple PCR-RFLP method for genotyping of IFNL4 rs368234815 polymorphism in patients with chronic hepatitis C. Lab Med. 2017;48:51-6.

30. Rosenbloom KR, Sloan CA, Malladi VS, et al. ENCODE data in the UCSC genome browser: year 5 update. Nucleic Acids Res. 2013;41:D56-63.

31. Kulakovskiy IV, Vorontsov IE, Yevshin IS, et al. HOCOMOCO: expansion and enhancement of the collection of transcription factor binding sites models. Nucleic Acids Res. 2016;44:D116-25.

32. Mathelier A, Fornes O, Arenillas DJ, et al. JASPAR 2016: a major expansion and update of the open-access database of transcription factor binding profiles. Nucleic Acids Res. 2016;44:D110-5.

33. Weirauch MT, Yang A, Albu M, et al. Determination and inference of eukaryotic transcription factor sequence specificity. Cell. 2014;158:1431-43.

34. Grant CE, Bailey TL, Noble WS. FIMO: scanning for occurrences of a given motif. Bioinformatics. 2011:27:1017-8.

35. Benson DA, Karsch-Mizrachi I, Lipman DJ, Ostell J, Wheeler DL. GenBank Nucleic Acids Res. 2005:33:D34-8.

36. UniProt Consortium. UniProt: a hub for protein information. Nucleic Acids Res. 2015:43:D204-12.

37. Barrett JC, Fry B, Maller J, Daly MJ. Haploview: analysis and visualization of LD and haplotype maps. Bioinformatics. 2005;21(2):263-5.

38. Benjamini Y, Hochberg Y. Controlling the false discovery rate: a practical and powerful approach to multiple hypothesis testing. J R Stat Soc B. 1995; 57:289-300.

39. Vaziri ND, Pahl MV, Crum A, Norris K. Effect of uremia on structure and function of immune system. J Ren Nutr. 2012;22:149-56.

40. Świątek-Kościelna B, Kałużna E, Strauss E, et al. Prevalence of IFNL3 rs4803217 single nucleotide polymorphism and clinical course of chronic hepatitis C. World J Gastroenterol. 2017;23:3815-24. 
41. de Castellarnau M, Aparicio E, Parera M, Franco S, Tural C, Clotet B, Martínez MA. Deciphering the interleukin $28 \mathrm{~B}$ variants that better predict response to pegylated interferon- $a$ and ribavirin therapy in HCV/HIV-1 coinfected patients. PLoS One. 2012;7:e31016.

42. Vergara $C$, Duggal $P$, Thio $C L$, et al. Multi-ancestry fine mapping of interferon lambda and the outcome of acute hepatitis $C$ virus infection. Genes Immun. 2020;21(5):348-59.

43. Lapa D, Garbuglia AR, Capobianchi MR, Del Porto P. Hepatitis C virus genetic variability, human immune response, and genome polymorphisms: which is the interplay? Cells. 2019;8(4):305.

44. Obajemu AA, Rao N, Dilley KA, et al. IFN- $\lambda 4$ attenuates antiviral responses by enhancing negative regulation of IFN signaling. J Immunol. 2017;199(11): 3808-20.

45. O'Brien TR, Prokunina-Olsson L, Donnelly RP. IFN- $\lambda 4$ : the paradoxical new member of the interferon lambda family. J Interf Cytokine Res. 2014;34(11): 829-38.

46. Chaturvedi $\mathrm{N}$, Svarovskaia ES, Mo $\mathrm{H}$, et al. Adaptation of hepatitis $\mathrm{C}$ virus to interferon lambda polymorphism across multiple viral genotypes. Elife. 2019; 8:e42542.

47. Cho YK, Kim YN, Song BC. Predictors of spontaneous viral clearance and outcomes of acute hepatitis C infection. Clin Mol Hepatol. 2014;20(4):368-75 Erratum in: Clin Mol Hepatol. 2015;21(1):104.

48. Liu L, Fisher BE, Thomas DL, Cox AL, Ray SC. Spontaneous clearance of primary acute hepatitis $C$ virus infection correlated with high initial viral RNA level and rapid HVR1 evolution. Hepatology. 2012;55(6):1684-91.

49. Kent WJ, Sugnet CW, Furey TS, Roskin KM, Pringle TH, Zahler AM, Haussler D. The human genome browser at UCSC. Genome Res. 2002;12:996-1006.

50. Tang W, Wallace TA, Yi M, et al. IFNL4- $\Delta$ G allele is associated with an interferon signature in tumors and survival of African-American men with prostate Cancer. Clin Cancer Res. 2018;24(21):5471-81.

51. Onabajo OO, Wang F, Banday R, Prokunina-Olsson L. Tumor transcriptome analysis and immune infiltrate profiling suggests a role for the IFNL3/IFNL4 genomic locus in liver cancer. J Immunol. 2018;200(1 Supplement):178.

52. Lasfar A, Zloza A, Silk AW, Lee LY, Cohen-Solal KA. Interferon lambda: toward a dual role in cancer. J Interf Cytokine Res. 2019;39:22-9.

53. PLAG1 like zinc finger 1 [ Homo sapiens (human) ]. Available at: https:// www.ncbi.nlm.nih.gov/gene/5325. Accessed 24 Nov 2019.

\section{Publisher's Note}

Springer Nature remains neutral with regard to jurisdictional claims in published maps and institutional affiliations.

Ready to submit your research? Choose BMC and benefit from:

- fast, convenient online submission

- thorough peer review by experienced researchers in your field

- rapid publication on acceptance

- support for research data, including large and complex data types

- gold Open Access which fosters wider collaboration and increased citations

- maximum visibility for your research: over $100 \mathrm{M}$ website views per year

At $\mathrm{BMC}$, research is always in progress.

Learn more biomedcentral.com/submissions 